\title{
Investigación, comunicación y publicación en las universidades del siglo XXI: Actualidad y desafíos
}

Leticia Salomón*

\section{A. EL CONTEXTO DE LAINVESTIGACIÓNENEL S. XXI}

El S.XXI presenta un conjunto de desafíos para las universidades, basado en cuatro aspectos clave: comparación, evaluación, acreditación y vinculación, los cuales se detallan a continuación:

\section{Comparación}

Cada vez se institucionaliza más la comparación entre universidades del mundo, basada en indicadores concretos que permiten conformar los famosos "Ranking" de universidades con los cuales nos ubicamos a nivel mundial, continental, regional y nacional, y vemos la distancia que nos separa de las demás universidades, tratando de encontrar las razones que impulsan a algunas de ellas hacia los primeros lugares y las que las impulsan hacia los últimos lugares. Es indudable que la ubicación en un lugar 0 en otro obedece a razones institucionales y nacionales que se producen a nivel histórico y coyuntural. A la cabeza de esto se encuentra el momento en que una universidad decide, por cualquier razón, iniciar un proceso de reforma que le permita impulsar un proceso de modernización con la direccionalidad de una visión estratégica, en una combinación de liderazgos fuertes, procesos dinámicos y sostenibilidad de las iniciativas.

Un segundo nivel explicativo radica en el papel que juega el gobierno central a través de sus organismos de ciencia y tecnología, y su capacidad de estimular, apoyar y potenciar el papel de las universidades en el desarrollo del país. Un tercer nivel se relaciona con las características del personal docente y administrativo con que cuenta la universidad, la forma en que se desempeña, los papeles que juega y los valores culturales con que se desempeña.

\section{Evaluación}

El desempeño de las universidades se convierte en el centro de la atención. De ahí la importancia de precisar la cantidad y calidad de lo que se tiene, y de identificar lo que no se tiene. Planes de estudios, profesores, estudiantes y capacidades institucionales se ponen a prueba y se evalúa su capacidad competitiva y su potencialidad para contribuir al desarrollo de un país. Las evaluaciones internas y externas se ponen a la orden del día

\footnotetext{
${ }^{1}$ Universidad Nacional Autónoma de Honduras. Dirección de Investigación Científica investigacionunah.directora.Is@gmail.com
} 
para valorar si la universidad está cumpliendo con la demanda de la sociedad del conocimiento y las exigencias de una sociedad en desarrollo, en una época en que el conocimiento se multiplica con la velocidad de las comunicaciones y deja obsoletos los conocimientos que hasta entonces se consideraban adecuados y modernos.

\section{Acreditación}

La capacidad de anunciar las cualidades y condiciones de una universidad pasa por la acreditación de su potencialidad y la obligación de certificar la calidad y pertinencia de sus productos, aspecto que le da sustento a su prestigio como universidad y la convierte en referente para padres y estudiantes que buscan las mejores opciones para sus hijos. Surge la necesidad de que los acreditadores sean externos a la propia universidad para que prevalezca la objetividad, el tecnicismo y la rigurosidad de los procedimientos en la valoración de los indicadores clave y proporciona la confianza necesaria para saber que las características con que se anuncia sean las correctas.

\section{Vinculación}

Surge la necesidad de superar la visión de universidad encerrada y distante del mundo, y se plantea la exigencia de una universidad que responda a los desafíos del desarrollo nacional y a la demanda del desarrollo científico y tecnológico. Se espera una universidad vinculada al Estado, a los sectores productivos, a los sectores sociales y a las otras universidades nacionales e internacionales, conformando lazos disciplinarios, inter y transdisciplinarios que le permitan ampliar su visión y construir de forma conjunta con profesores, investigadores y estudiantes, esa visión global con la cual se vinculan al país, la región o el mundo.

\section{B. LANECESIDAD DE PROFESORES-INVESTIGADORES}

El contexto en el que se desempeñan las universidades del S. XXI plantea la necesidad de superar la etapa de repetición de conocimientos producidos en otras circunstancias y en otras sociedades, y comenzar a generar conocimiento que pueda ser transferido a la sociedad y contribuya a la solución de los problemas nacionales. Esto sólo es posible con el desarrollo de la investigación científica que permita la transformación de los docentes universitarios en profesores- investigadores, es decir, en profesores que, además de dedicarse a la docencia, se conviertan en generadores de conocimiento con rigurosidad y pertinencia. Este punto es clave para comenzar a superar los límites de una universidad de docencia y hacer realidad el desarrollo de las tres funciones básicas de la misma, como son la docencia, la investigación y la vinculación.

Es indudable que éste no es un proceso fácil porque supone la construcción de una cultura de investigación que no siempre viene asociada a los grados obtenidos y que supone eliminar la concepción tradicional de que los profesores universitarios se contratan y se 
nombran únicamente para impartir clases. Este proceso puede ser relativamente fácil en aquellos que están entrando a la universidad y que tienen pocos años de haberse incorporado a la misma; pero suele ser más difícil en los profesores que tienen varios años de estar dedicados solamente a la docencia universitaria y mucho más con los que se encuentran en la etapa previa a su jubilación. Esto implica una atención diferenciada entre los que necesitan formarse en posgrados para afianzar el dominio de su disciplina científica, los que requieren capacitarse para asegurar el manejo metodológico y técnico de los procesos de investigación, los que necesitan apoyo institucional para iniciarse como investigadores o para potenciar las líneas de investigación que vienen desarrollando desde hace muchos años. Lo importante es propiciar, estimular y apoyar el desarrollo de la investigación científica en cada disciplina que se atiende en la universidad, más allá de la cantidad de profesores involucrados en esta tarea, la que puede ser muy pequeña al principio pero debe ser cada vez más grande con el paso del tiempo, conforme se desarrolle la cultura de la investigación en una universidad.

\section{La importancia de comunicar los resultados}

Este proceso de adaptación al perfil de una universidad del S.XXI, en particular en la función de investigación, requiere de cuatro fases debidamente diferenciadas: investigar, comunicar, publicar y transferir conocimiento nuevo (ver gráfico No. 1). La investigación que se queda atrapada en un escritorio o en un laboratorio no cumple con su razón de ser que es la trascendencia. Por ello es importante comunicar los resultados de las investigaciones y esto supone someter los hallazgos a la consideración de los pares, presentando ponencias 0 posters en eventos universitarios, nacionales 0 internacionales.

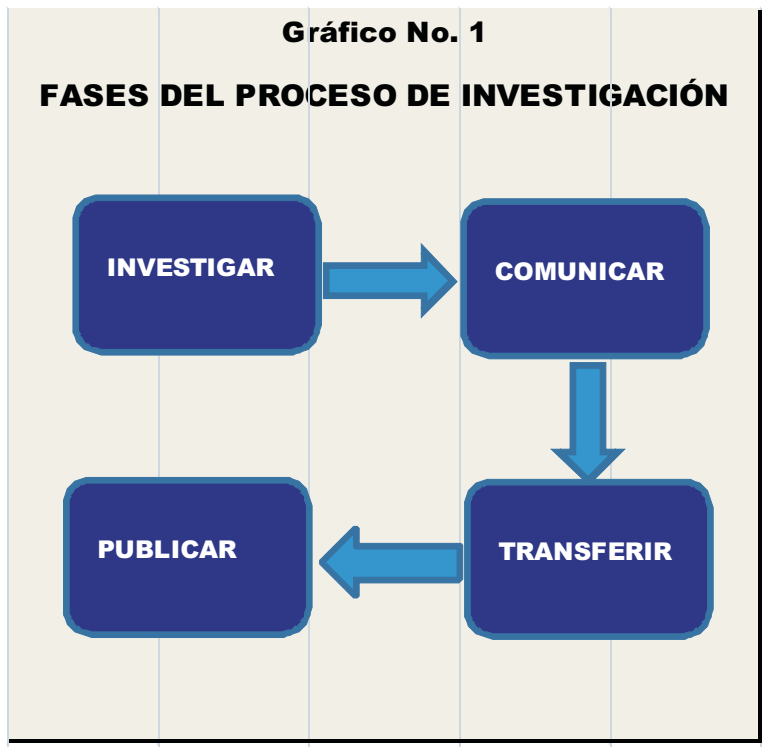


Esta fase requiere la intensificación del debate académico propiciando espacios para el mismo, lo que se produce a través de encuentros, foros, talleres, simposios, conferencias y congresos (ver gráfico No. 2), dependiendo de la modalidad y rigurosidad con que se aspire a presentar los resultados de las investigaciones. Esta fase de comunicación es fundamental para dar a conocer lo que se ha encontrado pero también para someter a prueba los resultados con los pares, es decir, con aquellos que comparten el estudio de una disciplina o de una línea de investigación, proceso que puede realizarse a nivel interno de una universidad, a nivel nacional e internacional. La cantidad y calidad de estos encuentros académicos en una unidad o en una universidad sirve de medidor de la intensidad de la dedicación a la investigación científica, lo que implica una obligación institucional de apoyarlos y promoverlos pues sirven, además, para dar a conocer a la sociedad y al mundo el interés en promover y apoyar la actividad científica en una universidad determinada.

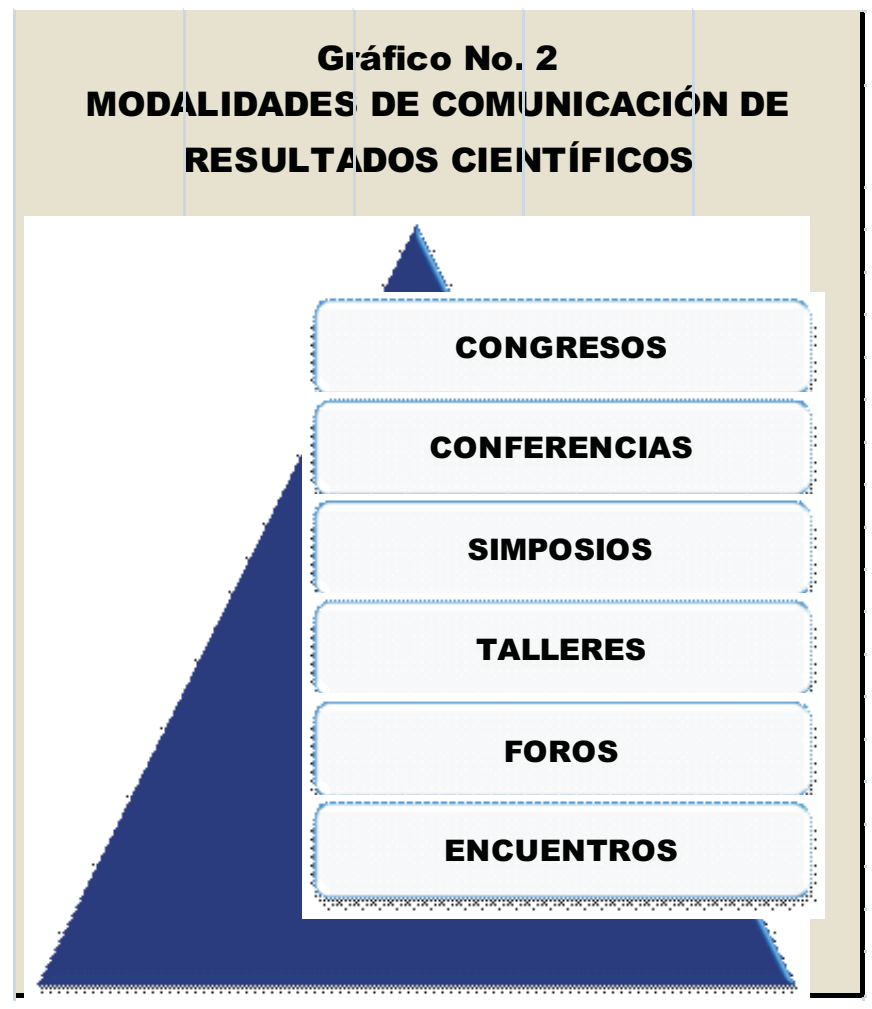

\section{La obligación de publicar los resultados}

La comunicación de resultados es la antesala obligada de una fase ineludible como es la publicación en revistas universitarias, nacionales e internacionales. La comunicación de resultados en cualquiera de sus modalidades debe verse como una fase previa a la 
publicación pues ésta se convierte en la concreción de un hallazgo o de un planteamiento que fue discutido y sometido a prueba con los respectivos pares. La clave está en crear esas instancias de publicación científica, debidamente acreditadas nacional e internacionalmente y constantemente evaluadas para asegurar su calidad. La universidad debe propiciar, estimular y apoyar la combinación de publicaciones universitarias con difusión externa, las publicaciones nacionales y las publicaciones internacionales, para cumplir con el doble objetivo de visibilizar la universidad en cuanto al desarrollo científico y tecnológico, y en cuanto su capacidad de contribuir al conocimiento de los problemas nacionales y propiciar la mejores decisiones orientadas a su solución.

El propósito de publicar a nivel interno y nacional es potenciar a la universidad y sus investigadores como referentes en determinados temas de mucha sensibilidad nacional, mientras la publicación internacional, sobre todo la que se ubica en las revistas de mayor impacto en el mundo científico, es visibilizar a la universidad y a sus investigadores como referentes en el mundo de la ciencia, la tecnología y la innovación. Para todo esto tiene que prepararse una universidad, pues no puede publicarse una revista si no tiene investigadores que la hagan sostenible y no puede publicar artículos con el sello universitario si estos no han acreditado su rigurosidad científica y su adecuado abordaje metodológico y técnico.

\section{La responsabilidad de transferir conocimientos}

El proceso de investigar, comunicar y publicar quedaría incompleto sin la fase de la transferencia. Los resultados de una investigación deben llegar a sus destinatarios, ya sea a nivel de Estado en sus distintas secretarías e instancias, o a nivel de los sectores productivos 0 a nivel de los sectores sociales que requieren de esos conocimientos nuevos o innovadores para su utilización y aplicación inmediata. La transferencia incluye desde la colocación de ideas, propuestas y recomendaciones en los tomadores de decisiones (incidencia política) hasta la divulgación de una innovación, la creación de un nuevo proceso o la consecución de un nuevo producto, pasando por la capacitación que se traduzca en mejores prácticas.

La transferencia de conocimientos se constituye en el punto clave de la vinculación universidad-sociedad y, por lo tanto, se convierte en otra de las responsabilidades institucionales creando puentes, abriendo canales de comunicación y estrechando relaciones con las diferentes instancias de la sociedad en su diversidad social, económica y política.

\section{DESAFÍOS PARA LAS UNIVERSIDADES Y LOS INVESTIGADORES}

Ser una universidad del S. XXI supone enfrentar enormes desafíos que apuntan directamente a la razón de ser de la universidad y el aseguramiento de sus tres funciones 
básicas. En cuanto a la función de investigación -investigación científica para ser más precisos- involucra un rediseño del perfil de ingreso, permanencia y ascenso en la carrera de profesor universitario, de manera que la investigación se convierta en parte natural de su condición de profesor del máximo nivel educativo, contribuyendo de esa manera a elevar el perfil investigativo de la universidad y a mejorar sus ubicación en los rankings nacionales e internacionales.

Investigar, comunicar, publicar y transferir conocimientos, deben ser un eje central del desempeño de un profesor-investigador en una universidad. A ésta le corresponde proporcionar la direccionalidad, el estímulo, el seguimiento y la evaluación, para asegurar la calidad de cada una de estas fases y facilitar la mejor acreditación de las mismas. 